\title{
PROCESSO DE ANÁLISE DE VIABILIDADE DE FRANQUIA DO TIPO SHOP IN SHOP EM POSTOS DE GASOLINA
}

Luis Furtado ${ }^{1}$

Romain Cailleau ${ }^{1}$

Antonio Artur De Souza ${ }^{1}$

${ }^{1}$ Universidade Federal de Minas Gerais 


\section{PROCESSO DE ANÁLISE DE VIABILIDADE DE FRANQUIA DO TIPO SHOP IN SHOP EM POSTOS DE GASOLINA}

Resumo: O presente trabalho analisa a viabilidade financeira da abertura de um novo negócio de franquia shop in shop chamada "Pit Stop Skol", da multinacional brasileira AMBEV, na cidade de Belo Horizonte. Dados foram coletados junto ao proprietário de uma franquia já em funcionamento e três cenários foram criados para o negócio. No primeiro, o fluxo de caixa e o modo de operação do novo negócio é idêntico à realidade da franquia já existente. Já o segundo inclui despesas (aluguel e mão-de-obra extra) que não são consideradas no primeiro cenário. Enfim, o último cenário apresenta duas modificações nas despesas: a inclusão de aluguel e a remuneração do sócio. Uma comparação dos três cenários mostra que o primeiro é o mais viável. Porém, o terceiro é também muito atraente na medida que não há necessidade do investidor ser proprietário de um posto de gasolina.

Palavras-chave: Análise de Viabilidade. Empreendedorismo. Franquias Shop in Shop. Pit Stop Skol.

\section{$1 \quad$ Introdução}

Estudos realizados pelo Serviço Brasileiro de Apoio às Micro e Pequenas Empresas SEBRAE (2016) apontam que 23,4\% das empresas constituídas em 2012 fecham a porta com menos de dois anos de existência, chegando tal estatística a $45 \%$ para microempresas. Os três principais motivos de insucesso listados pelo SEBRAE são: falta de planejamento, gestão empresarial inadequada e falta de comportamento empreendedor. Já este último se relaciona à falta de planejamento na medida que é caracterizado pela falta de plano de ações e de metas definidas para atingir os objetivos. No que tange aos problemas de planejamento, o SEBRAE (2014) informa que 55\% das novas empresas brasileiras não elaboram planos de negócios.

Reconhecida como forma de empreendimento, o franchising já se estabeleceu como uma alternativa importante apresentando maiores chances de sobrevivência para novos empreendedores brasileiros. Segundo a Associação Brasileira de Franchising (ABF), existem mais de 140 mil franquias no Brasil, as quais empregam mais de 1,3 milhão de trabalhadores em 2018. Essas franquias apresentam uma taxa de mortalidade de $3,9 \%$, contra $5 \%$ no ano anterior, e são responsáveis por aproximadamente R\$ 170 bilhões em venda no Brasil, representando assim um terço das vendas no varejo. O crescimento do franchising no Brasil pode ser explicado pelo fato de as franquias beneficiarem tanto o franqueado como o franqueador. Por um lado, o franqueado pode ser seu próprio patrão e ter uma certa forma de segurança operacional e financeira, além de se beneficiar da imagem da marca já reconhecida. Por outro lado, o franchising reduz os problemas de recrutamento, facilita o monitoramento da nova unidade e oferece uma expansão rápida com investimento inicial mínimo para o franqueador (FULOP; FORWARD, 1997; SCHREIBER; SZYSZKO, 2014).

Embora que as franquias sejam muito atraentes, elas ainda apresentam fatores de fracasso semelhantes aos enfrentados pelas pequenas empresas, como destacado por Machado 
e Espinha (2010). Dessa forma, a necessidade de um planejamento prévio se mostra como um dos aspectos mais cruciais para o sucesso da nova empresa. O plano de negócios é uma ferramenta que o empreendedor deve utilizar para conhecer melhor o próprio negócio, assim como o ambiente em que ele está localizado, e, principalmente, para reduzir riscos de insucesso por meio da análise de viabilidade financeira.

Tendo em vista a importância das franquias para o desempenho da economia brasileira, uma pesquisa para analisar a viabilidade financeira de novos tipos de franquias mostra-se atual e necessária para minimizar os riscos de fracasso. Para tanto, o presente trabalho analisa a possibilidade da abertura de um novo negócio de franquia shop in shop chamada "Pit Stop Skol", da multinacional brasileira AMBEV, na cidade de Belo Horizonte, a ser localizado na região centro-sul da cidade. Para atingir o objetivo principal deste trabalho, foram propostos os seguintes objetivos específicos: (a) identificar e descrever os investimentos, custos e despesas necessários para atender a demanda estimada e (b) descrever o processo de análise de viabilidade.

Espera-se, por meio deste estudo de caso, auxiliar os investidores na realização da análise de viabilidade, destacando pontos importantes e oferecendo soluções frente aos problemas específicos do processo de análise. Além disso, este estudo poderá servir de base a tomada de decisão de abertura de uma nova franquia, sendo relevante na medida em que tal negócio tem se apresentado como alternativa viável para a geração complementar de renda. Com base em uma pesquisa bibliográfica, constatou-se que não há artigos, na literatura acadêmica, que usam dados empíricos de uma franquia existente para analisar a viabilidade de uma nova franquia.

O presente artigo conta com duas seções (2 e 3) de revisão da literatura, sobre franquias e falência. A seção 4 apresenta a metodologia e a 5 uma descrição da franquia Pit Stop Skol. Na seção 6 são apresentados e analisados os resultados da pesquisa, destacando os três cenários de análise e depois comparando-os. Na seção 7 são apresentadas as conclusões da pesquisa.

\section{Desenvolvimento das Franquias}

A literatura sobre franchising oferece duas principais razões para o desenvolvimento deste modus operandi através da teoria da agência e da teoria da escassez dos recursos. Segundo a teoria da agência, existem conflitos de interesses entre o franqueador e o franqueado, que maximizam suas próprias utilidades. $\mathrm{O}$ uso de franquias é conhecido por reduzir os efeitos do shirking, segundo o qual o gerente responsável pela expansão da rede faz menos esforços quando seu salário não depende do retorno da nova unidade, e do perquisitetaking, segundo o qual o gerente procura maximizar seus ganhos por meior de benefícios como deslocações ao estrangeiro, na medida que as ações do franqueado têm um efeito direto na própria renda. Entretanto, franchising também apresenta custos de agência decorrentes da tomada insuficiente de risco quando o franqueado não tiver um portfólio diversificado, de comportamentos oportunistas e do problema de free-riding no qual o franqueado aproveita da imagem da marca enquanto oferece uma qualidade menor. Consequentemente, a escolha entre franquias e lojas próprias resulta do trade-off entre benefícios e custos de agência (BRICKLEY; DARK, 1987; BRICKLEY; DARK; WEISBACK, 1991). 
Quanto à teoria da escassez dos recursos, as franquias são vistas como fontes de capital com baixo custo que permitem ao franqueador captar recursos (NORTON, 1988). O uso de franquias permite aos novos negócios ter um acesso rápido e barato a novos mercados. Como novos negócios precisam de um crescimento alto para competir com negócios já estabelecidos, o franchising alivia tais restrições relacionadas ao crescimento como a falta de recursos financeiros ou de gerentes treinados. $\mathrm{O}$ franchising também permite transferir o risco do franqueador para o franqueado (OXENFELDT; KELLY, 1968; FULOP; FORWARD, 1997). Essa teoria foi criticada por Rubin (1978), demonstrando que a captação de recursos junto a investidores passivos seria mais eficiente e que a necessidade de capital não é o único motivo do porquê as empresas usam franquias. Entretanto, Combs e Ketchen (1999) mostraram que franquias com escassez de recursos tiveram uma expansão maior de que aquela sugerida pelas variáveis relacionadas à teoria da agência. Eles afirmam que é necessário combinar as diferentes teorias para poder explicar os comportamentos das franquias.

$\mathrm{Na}$ tentativa de explicar os fenômenos observados no mercado das franquias, a literatura tem tido foco no ponto de vista do franqueador e dá pouca atenção ao papel do franqueado. Alguns artigos tentaram explicar a decisão do franqueado por meio de um estudo dos contratos e dos incentivos associados (e.g., LUTZ, 1995). Porém, a decisão do franqueado em si foi pouca estudada. Kaufmann (1999) estuda o processo que leva um empreendedor a comprar uma franquia. Ele nota que o franqueado, ao contrário do franqueador, se apresenta como uma pessoa física com esperança de vida finita, recursos limitados, metas pessoais, e experiências de vida idiossincráticas. Assim, a decisão de comprar uma franquia decorre da decisão de trabalhar por conta própria. Embora independente, o empreendedor ainda pode abrir um novo negócio ou comprar um negócio já existente. Todavia, a decisão de comprar uma franquia está relacionada aos benefícios financeiros e comerciais da franquia. Por exemplo, ao comprar uma franquia, o franqueado se beneficia da imagem da marca, do knowhow da empresa franqueadora e das instalações padronizadas. Enfim, Kaufmann mostra que a franquia permite a pequenos investidores entrar em mercados novos na medida que franqueados são mais aptos a comprar uma franquia em um setor desconhecido.

\section{$3 \quad$ Falência}

Embora amplamente estudado, o tema da falência das franquias tem criado opiniões divergentes acerca da definição do conceito de falência. Há diferenças nas estimações das taxas de mortalidade das franquias, de acordo com estudos anteriores. O problema da coleta de dados no caso das redes de franquias foi evidenciado por Frazer (2001). No intuito de reconciliar os resultados da literatura, Holmberg e Morgan (2003) desenvolveram uma noção mais ampla de falência, segundo a qual a falência é vista como um processo contínuo constituído por diferentes etapas. Nas primeiras etapas, já se pode perceber um problema gerencial e um conflito entre o franqueado e o franqueador. Nas etapas intermediárias, existem problemas de pagamento de royalties e dos fornecedores. Enfim, as últimas etapas estão relacionadas ao encerramento do contrato e/ou da franquia e às perdas para credores. Os autores ressaltam que nem toda falência passa por todas as etapas. Eles afirmam ainda que é importante estudar a falência com base em todas suas manifestações e também com base nos artigos que abordam essas manifestações de forma individual. 
Uma vez esclarecido o fato de a falência ser um processo complexo que inclui também partes interessadas além do franqueado e franqueador, é importante determinar os fatores que levam uma franquia a entrar em tal processo. Os determinantes de fracasso têm sido estudados de forma dispersa, uma vez que os artigos procuram explicar algumas manifestações do processo de falência. Por exemplo, Azoulay e Shane (2001) estudaram o impacto de cláusulas de territórios exclusivos sobre a sobrevivência das franquias e focaram na relação franqueadofranqueador. Após o estudo de 170 contratos de franquias e entrevistas de 16 fundadores de redes de franquias, eles mostraram que a proteção oferecida pelos franqueadores diminui o fracasso das franquias. No estudo deles, houve empreendedores que não adotaram essa política por causa dos seus conhecimentos limitados sobre a contratação, mostrando assim a importância da etapa de elaboração do contrato para o sucesso da franquia.

O papel do franqueador é de altíssima importância para o bom sucesso do franqueado. Michael e Combs (2008) examinaram como as ações do franqueador afetam a sobrevivência das franquias. Eles mostram que o risco de fracasso está relacionado de forma negativa com o desempenho do franqueador e com territórios exclusivos. Ao contrário, o risco de fracasso é relacionado de forma positiva com o investimento inicial e a taxa de royalties. Esses resultados estão de acordo com a teoria da agência. A teoria de escassez de recursos também recebeu suporte, pois ambos a duração de treinamento e o investimento do franqueador na imagem de marca foram relacionados de forma negativa. Dessa forma, o franqueador pode investir em recursos estratégicos, caraterizados como recursos escassos, imperfeitamente imitáveis e não-substituíveis, para aumentar as chances de sucesso da franquia. Entretanto, não existem interações entre esses investimentos e o efeito da taxa de royalties.

Poucos artigos se interessaram com o ponto de vista do franqueado. Entre esses, destaca-se o trabalho de Machado e Espinha (2010) que questionaram 39 ex-franqueadores sobre a importância de vários fatores de fracasso. Segundo os participantes, o fator mais importante é o resultado financeiro insuficiente, que pode resultar de uma má gestão, de uma elaboração do contrato ineficiente e/ou de uma análise errada do negócio. De acordo com Boyle (2002), mais do que o resultado financeiro, são o planejamento insuficiente e as projeções erradas do resultado que podem levar à falência da franquia. Outros fatores muito importantes estão relacionados à falta de apoio e conflitos com franqueadores. Enfim, os outros fatores destacados fazem referência à falta de planejamento e à gestão empresarial inadequada.

\section{$4 \quad$ Método de Pesquisa}

O presente trabalho é um estudo de caso que pode ser classificado, segundo Lakatos e Marconi (2003), como descritivo e ex-post facto, com abordagem quantitativa de dados, pois uma análise de viabilidade foi realizada com base em informações do passado. Neste trabalho, utilizou-se a técnica de pesquisa documental, segundo a qual os materiais usados não foram ainda tratados de forma analítica.

Com intuito de aproximar as estimativas de vendas da realidade, foram utilizados dados de uma franquia Pit Stop Skol que está em funcionamento no Posto Comboio localizado na cidade de Araxá, Minas Gerais. Os dados utilizados para elaboração deste trabalho foram informações de vendas e mix de produtos, despesas e receitas e resultados da franquia existente. As informações foram coletadas por meio do sistema de informação do 
Posto Comboio, chamado "Petros" e produzido pela empresa de tecnologia de informação Hitec.

Foram realizadas entrevistas com o proprietário do negócio Pit Stop Skol do Posto Comboio para coletar dados operacionais, financeiros e mercadológicos. As entrevistas serviram também para conhecer as experiências gerais sobre a relação entre o franqueado e o franqueador AMBEV. Após as entrevistas e a coleta de dados do negócio existente, foram desenvolvidos três cenários possíveis para o negócio, com base em três diferentes estimativas de vendas.

No primeiro cenário, a nova franquia utiliza-se os dados obtidos junto ao Posto Comboio para elaboração de uma previsão de venda e de custos, ou seja, o fluxo de caixa e o modo de operação do novo negócio é idêntico à realidade desse posto que já conta com uma franquia Pit Stop Skol.

No segundo cenário do novo empreendimento, estima-se um valor mínimo de vendas para um payback em até 12 meses. O modelo de negócio do segundo cenário conta com despesas (aluguel e mão-de-obra extra) que não são consideradas no primeiro cenário.

Finalmente, no terceiro cenário, é proposto a possibilidade de uma sociedade e, assim, as estimativas de vendas e custos do novo negócio são baseadas nos demonstrativos do Pit Stop Comboio, porém o novo negócio apresenta duas modificações nas despesas: a inclusão do aluguel e a remuneração do sócio.

Técnicas de avaliação de projetos de investimento foram empregadas para analisar a viabilidade financeira do negócio: valor presente líquido (VPL), taxa interna de rentabilidade (TIR) e payback descontado. O VPL procura determinar o valor presente do investimento calculando a diferença entre a soma dos fluxos de caixa descontados e o custo do investimento inicial. Usando esse método, qualquer investimento que tem um VPL positivo é considerado como viável. Esse método leva em consideração o valor do dinheiro no tempo, empregando uma taxa de desconto aos fluxos de caixa.

Entretanto, o conceito de VPL é insuficiente para poder captar todas as dimensões do investimento. Já a TIR corresponde à taxa de desconto que permite zerar o VPL. Esse conceito analisa a atratividade do investimento, ao compará-lo com a taxa de retorno mínima exigida pelos investidores. Dessa forma, assim que a TIR for maior que a taxa mínima de atratividade, o projeto é considerado viável. A TIR também pode ser usada para comparar diferentes alternativas de investimentos. Neste caso, a alternativa que apresentar a maior TIR será a escolhida.

Embora ofereçam informações complementares, esses dois conceitos não levam em consideração a dispersão dos fluxos de caixa no tempo. Por exemplo, um projeto de 10 anos tendo somente fluxos de caixa importantes nos últimos anos pode apresentar VPL e TIR que indiquem viabilidade do projeto, mas na prática tal projeto poderia não ser sustentável para o proprietário nos primeiros anos. Por isso, a técnica do payback descontado permite determinar o período necessário para que o investimento inicial seja reembolsado pelos fluxos de caixa descontados. Assim, para certos investidores, quanto menor o período de payback, melhor o investimento. 


\section{A Franquia Pit Stop Skol}

A AMBEV, em 2012, decidiu franquear um novo conceito de negócio, chamado Pit Stop Skol, com um enorme potencial de crescimento. A ideia principal do modelo de negócio é sugerida intuitivamente pelo nome da franquia, ou seja, uma parada rápida para levar a bebida gelada para casa. A franquia Pit Stop Skol tem o foco na venda de cervejas em embalagens retornáveis, geladas e para o consumo em casa. Ela é feita para ser agregada a um negócio já existente e por isso é considerada como do tipo shop in shop. Desde 2012, a franquia vem expandindo e já conta com mais de 300 unidades em todo o Brasil, segundo consulta no site da AMBEV em 2018.

Dessa maneira, o Pit Stop da Skol promove a venda de bebidas da AMBEV, sendo ela não limitada a cervejas e não limitada à marca Skol. A AMBEV também oferece em seu portfólio mais de 25 marcas de cervejas, dentre elas as marcas Skol, Brahma e Antártica, as quais tem uma ótima aceitação nacional. A multinacional AMBEV conta também com mais de 30 marcas de bebidas não alcoólicas que podem ser vendidos nesse modelo de franquia. Entretanto, o foco do negócio é a venda de bebidas alcoólicas em garrafas de 300 mililitros retornáveis, segundo informações da plataforma online da empresa.

O Pit Stop Skol é um container refrigerado adesivado. O franqueador sugere a instalação em grandes áreas internas ou externas, tais como postos de gasolina, Shoppings Centers, estacionamentos ou em qualquer outro ponto comercial aprovado pela franqueadora AMBEV. O container é entregue já devidamente plotado pela Franqueadora, pronto para funcionamento, não possuindo gerador, necessitando assim de um ponto bifásico de energia elétrica no local em que for instalado, segundo AMBEV (2018). O contêiner conta com 1 (um) ano de garantia, observado que pode ser necessário a realização de obra civil antes da instalação, dependendo das condições do piso em que este for instalado.

O investimento inicial da franquia pode variar de R $\$ 85$ mil até $\mathrm{R} \$ 96$ mil, sendo ele composto por R $\$ 85$ mil da Taxa de Adesão e de até R\$11 mil reais de obras de instalação, segundo informações do site AMBEV (2018). O franqueado também deve pagar Royalties de $6,5 \%$ em relação a alguns produtos AMBEV (entre eles a Brahma e Skol retornável). No entanto, é importante destacar que essa taxa inicial de franquia para clientes já franqueados é de R\$ 55 mil (ao invés de R\$ 85 mil).

No presente estudo, trabalhou-se com uma proposta de franquia Pit Stop Skol da AMBEV, chamada Pit Stop Skol Luxemburgo e instalada em um posto de gasolina localizado no bairro Luxemburgo, em Belo Horizonte (MG). O posto em questão não apresenta loja de conveniência e apresenta uma área apropriada para a instalação do container. O local escolhido apresenta fácil acesso e está localizado na rua principal do bairro com um grande fluxo de pessoas e carros. O bairro Luxemburgo mostra um mercado promissor na venda de bebidas alcoólicas, uma vez que o poder de consumo da região é alto e a densidade populacional do bairro é grande.

A forma jurídica escolhida foi a Empresa Individual de Responsabilidade Limitada (Eireli), uma vez que a sociedade será composta por apena um sócio e pelo fato do faturamento anual da empresa ser superior a R\$ 81 mil. Outra vantagem da Eireli é que permite a separação entre o patrimônio empresarial (isto é, da empresa) e o privado (isto é, do empresário). 
O Pit Stop Skol Luxemburgo será uma empresa de baixa margem e de alto volume. Portanto, foi escolhido o regime tributário Lucro Real, mais adequado para a futura realidade da empresa. A forma jurídica e o regime tributário da empresa deverão no futuro ser confirmados com o contador responsável para averiguar a eficiência das escolhas.

\section{$6 \quad$ Análise de Viabilidade Financeira \\ 6.1 Plano Financeiro}

Esta seção tem como foco a viabilidade financeira da franquia Pit Stop Skol Luxemburgo. Os três cenários definidos na seção Método de Pesquisa são apresentados e a analisados. O demonstrativo de vendas da franquia existente foi usado como base para elaborar uma previsão de vendas mais assertiva. O Mix de vendas do posto Comboio apresentou três principais produtos que representam $68,72 \%$ do valor total de vendas de produtos, sendo eles os "litrinhos" de Skol e Brahma e, também, a Skol lata. A lata está em promoção com a intenção de atrair o público e, assim, conhecerem o sistema dos litrinhos retornáveis do Pit Stop Skol.

No mês de dezembro, o litrinho da Brahma apresentou um valor de vendas brutas de $\mathrm{R} \$ 18.770,86$, com preço de venda médio de $\mathrm{R} \$ 1,67$ e custo médio de $\mathrm{R} \$ 1,27$. O lucro bruto deste item foi de $\mathrm{R} \$ 3.906,40$, com uma margem unitária de $\mathrm{R} \$ 0,35$ por unidade e uma margem de contribuição de $20,08 \%$.

Ainda na análise dos principais itens vendidos, o litrinho de Skol teve um total de vendas brutas de $\mathrm{R} \$ 15.634,33$, com preço de venda médio de $\mathrm{R} \$ 1,66$ e custo unitário médio de $\mathrm{R} \$ 1,28$. Dessa maneira, o lucro unitário da Skol foi de $\mathrm{R} \$ 0,35$ e o custo médio total de $\mathrm{R} \$ 12.024,47$, com uma margem de contribuição de $21,3 \%$.

A Skol lata teve uma participação significativa e, assim, apresentou um valor médio de vendas brutas de $\mathrm{R} \$ 22.735,34$, com lucro bruto total de $\mathrm{R} \$ 2.398,47$ e custo médio total de $\mathrm{R}$ \$ 20.294.21. O custo unitário das latas de Skol foi de R $\$ 1,78$ e o preço de venda de R\$ 1,99, gerando um lucro bruto unitário de R \$ 0,21 e uma margem de contribuição de 10,5\%.

$\mathrm{Na}$ análise geral de vendas do mês de dezembro, verificou-se a venda de 38.007 unidades, com vendais totais de $\mathrm{R} \$ 76.759,77$ e lucro bruto total de $\mathrm{R} \$ 14.938,44$. O custo médio unitário total das vendas do mês de dezembro foi de $\mathrm{R} \$ 1,63$, com um preço de venda de $\mathrm{R} \$ 2,02$ e uma margem de contribuição unitária de R\$ 0,39. Portanto, o mês de dezembro de 2017 apresentou uma margem de contribuição total de 19,5\%.

\subsubsection{Primeiro Cenário}

A Tabela 1 apresenta o Plano de Resultados, que destaca Receita Líquida (RL), o Custo das Mercadorias Vendidas (CMV), as Despesas Operacionais (DO), o Lucro Bruto (LB) e o Lucro Líquido (LL) da franquia Pit Stop Skol em funcionamento durante um ano. As despesas operacionais do primeiro cenário incluem apenas Royalties (RYT) e Energia Elétrica (EE). Foram considerados descontos para os clientes que completam o tanque (abastecem com mais de 30 litros) e para bares e restaurantes que compram no atacado. Tais descontos chegam a 10 centavos na unidade de litrinho. 
Tabela 1 - Plano de Resultados do Posto Comboio (2018)

\begin{tabular}{|l|c|c|c|c|c|c|}
\hline MÊS & DEZ-17 & JAN-18 & FEV-18 & MAR-18 & ABR-18 & MAI-18 \\
\hline$(=)$ RL & $76.759,77$ & $56.016,34$ & $59.843,85$ & $76.609,60$ & $79.013,80$ & $75.667,02$ \\
\hline$(-)$ CMV & $(61.821,33)$ & $(45.132,43)$ & $(48.186,20)$ & $(62.413,70)$ & $(64.510,09)$ & $(61.499,92)$ \\
\hline$(=)$ LB & $14.938,44$ & $10.883,91$ & $11.657,65$ & $14.195,90$ & $14.503,71$ & $14.167,10$ \\
\hline$(-)$ DO - RYT & $(1.713,83)$ & $(1.250,69)$ & $(1.336,15)$ & $(1.710,48)$ & $(1.764,16)$ & $(1.689,43)$ \\
\hline$(-)$ DO - EE & $(1.500,00)$ & $(1.500,00)$ & $(1.500,00)$ & $(1.500,00)$ & $(1.500,00)$ & $(1.500,00)$ \\
\hline$(=)$ LL & $11.724,61$ & $8.133,22$ & $8.821,50$ & $10.985,42$ & $11.239,55$ & $10.977,67$ \\
\hline MÊS & JUN-18 & JUL-18 & AGO-18 & SET-18 & OUT-18 & NOV-18 \\
\hline$(=)$ RL & $63.110,72$ & $67.816,84$ & $59.378,37$ & $68.246,26$ & $68.246,26$ & $68.246,26$ \\
\hline$(-)$ CMV & $(51.227,91)$ & $(55.134,67)$ & $(49.993,53)$ & $(55.546,64)$ & $(55.546,64)$ & $(55.546,64)$ \\
\hline$(=)$ LB & $11.882,81$ & $12.682,17$ & $9.384,84$ & $12.699,61$ & $12.699,61$ & $12.699,61$ \\
\hline$(-)$ DO - RYT & $(1.409,09)$ & $(1.514,16)$ & $(1.325,75)$ & $(1.523,75)$ & $(1.523,75)$ & $(1.523,75)$ \\
\hline$(-)$ DO - EE & $(1.500,00)$ & $(1.500,00)$ & $(1.500,00)$ & $(1.500,00)$ & $(1.500,00)$ & $(1.500,00)$ \\
\hline$(=)$ LL & $8.973,72$ & $9.668,01$ & $6.559,09$ & $9.675,87$ & $9.675,87$ & $9.675,87$ \\
\hline
\end{tabular}

Fonte: Elaborada pelos autores.

Ao analisar esta tabela, pode-se verificar que a receita média dos últimos nove meses do Pit Stop Comboio é de R\$ 68.246,26. Com essa receita, o negócio apresentou um lucro bruto médio de R $\$ 12.699,61$ e uma margem de contribuição de 18,61\%. As despesas do Pit Stop Skol Comboio são apenas os royalties e a energia elétrica. O valor dos royalties é de $6,5 \%$ do valor da compra das garrafas de $300 \mathrm{ml}$ retornáveis (litrinhos) e o valor das despesas com energia elétrica foi a média do aumento energético da conta de energia com a instalação do container refrigerado.

As despesas com software, mão de obra e contabilidade não foram levados em consideração, uma vez que a implementação do Pit Stop Skol Comboio não gerou acréscimos nessas despesas. Já que o gerente do posto de gasolina e da franquia Pit Stop é o mesmo, os recursos do posto de gasolina são usados para o bom funcionamento da franquia. Portanto, os frentistas são os responsáveis pelas vendas do Pit Stop Skol, e o valor da despesa com o software e a contabilidade continuou o mesmo já incluso nas despesas do posto. $\mathrm{O}$ valor da despesa com a contabilidade continuou inalterado por dois motivos: (i) não houve a necessidade de criação de um novo CNPJ para a venda de mercadorias do Pit Stop Skol Comboio; e (ii) o número de funcionários do posto continuou o mesmo.

Neste caso, as despesas de energia elétrica foram obtidas diretamente com o posto, uma vez que foram observadas as mudanças nos seus gastos agregados. Caso esse valor não estivesse disponível, seria possível calcular a despesa de energia elétrica usando o valor médio de consumo da franquia apresentado pela AMBEV e multiplicando-o pelo número de horas de funcionamento e pelo preço médio da energia na cidade.

A respeito da questão de tributos, o regime de tributação utilizado é o de Lucro Real, no qual o imposto de renda corresponde a uma taxa de $27.5 \%$ do lucro real. Como os valores são agregados, as despesas agregadas anulam o lucro da franquia Pit Stop, criando assim um prejuízo fiscal. Dessa forma, não é necessário pagar o imposto de renda sobre o lucro com a franquia Pit Stop Skol. Além disso, esse regime fica vantajoso na medida em que o faturamento aumenta. 
Após a retirada das despesas, verifica-se que o Pit Stop Comboio gerou um lucro líquido médio de $\mathrm{R} \$ 9.675,87$ nos primeiros oitos meses de operação, com margem de lucro líquido médio de $14,18 \%$. Esse valor médio foi usado no plano para os últimos meses por causa da falta de dados disponíveis na época. Com os valores mensais do lucro líquido, foi possível a criar um fluxo de caixa descontado a partir do investimento inicial, da necessidade de capital de giro e da reforma para a instalação do container.

Tabela 2 - Cálculo do Payback Descontado da Primeiro Cenário

\begin{tabular}{|c|c|c|c|c|c|c|}
\hline & NOV-17 & DEZ-17 & JAN-18 & FEV-18 & MAR-18 & ABR-18 \\
\hline Lucro líquido & 0 & $11.724,61$ & $8.133,22$ & $8.821,50$ & $10.985,42$ & $11.239,55$ \\
\hline $\begin{array}{l}\text { Custo da } \\
\text { franquia }\end{array}$ & $(10.000,00)$ & $(10.000,00)$ & $(10.000,00)$ & $(10.000,00)$ & $(10.000,00)$ & \\
\hline Reforma civil & $(5.000,00)$ & & & & & \\
\hline Capital de giro & $(15.455,33)$ & & & & & \\
\hline Fluxo de caixa & $(30.455,33)$ & $1.724,61$ & $(1.866,78)$ & $(1.178,50)$ & 985,42 & $11.239,55$ \\
\hline \multirow[t]{2}{*}{$\begin{array}{c}\text { Payback } \\
\text { descontado }\end{array}$} & $(30.455,33)$ & $(28.747,80)$ & $(30.577,79)$ & $(31.721,63)$ & $(30.774,66)$ & $(20.080 .62)$ \\
\hline & MAI-18 & JUN-18 & JUL-18 & AGO-18 & SET-18 & OUT-18 \\
\hline Lucro líquido & $10.977,67$ & $8.973,72$ & $9.668,01$ & $6.559,09$ & $9.675,87$ & $9.675,87$ \\
\hline Fluxo de caixa & $10.977,67$ & $8.973,72$ & $9.668,01$ & $6.559,09$ & $9.675,87$ & $9.675,87$ \\
\hline $\begin{array}{c}\text { Payback } \\
\text { descontado }\end{array}$ & $(9.739,16)$ & $(1.369,21)$ & $7.559,04$ & $13.556,28$ & $22.315,72$ & $30.988,43$ \\
\hline
\end{tabular}

Fonte: Elaborada pelos autores.

A partir de uma taxa de atratividade de 1\% mensal, calculou-se o VPL do projeto para um ano de fluxo de caixa e obteve-se um valor de R\$ 39.575.27. Essa taxa mínima de atratividade foi escolhida à partir das taxas livres de risco existente: CDI e poupança. Ao trazer o valor do fluxo de caixa ao valor presente do investimento, calculou-se o payback descontado e obteve-se um retorno de 8 meses, conforme visto na Tabela 2 . A taxa interna de retorno (TIR) do projeto foi de $12,02 \%$ para um ano de fluxo de caixa descontado, ou seja, a taxa foi doze vezes superior à taxa mínima de atratividade do projeto.

Em conclusão, o Pit Stop Skol Comboio mostrou-se lucrativo e rentável nos moldes em que está em funcionamento, ou seja, dando descontos para os clientes, contando com os funcionários do Posto Comboio e usando a estrutura do Posto Comboio, na qual não se paga aluguel.

\subsubsection{Segundo Cenário}

No segundo cenário para o negócio, levou-se em conta que o negócio não teria nenhum vínculo com os outros núcleos de negócios existentes no estabelecimento como, por exemplo, a revenda de combustível. Assim, levou-se em conta as seguintes despesas operacionais que não estão presentes no Pit Stop Skol Comboio: Despesa com Pessoal (DP) relativa a dois funcionários com remuneração de $\mathrm{R} \$ 1.100,00$ (com uma despesa empregatícia e adicional de periculosidade totalizando um acréscimo de 200\%), Despesa com Aluguel (DAl) no valor de R \$ 3.000,00 e uma taxa de manutenção de um Sistema de Informação (SI) 
para controle gerencial de $\mathrm{R} \$ 500,00$. As despesas com royalties de $6,5 \%$ no valor de compra dos litrinhos e com energia elétrica de $\mathrm{R} \$ 1.500,00$ também estão presentes neste cenário.

Tabela 3 - Plano de Resultados do Segundo Cenário

\begin{tabular}{|l|c|c|c|c|c|c|c|}
\hline \multicolumn{1}{|c|}{ Período } & SET-18 & OUT-18 & NOV-18 & DEZ-18 & JAN-19 & FEV-19 & MAR-19 \\
\hline$(=)$ RL & $115.139,66$ & $84.024,51$ & $89.765,78$ & $114.914,40$ & $118.520,70$ & $113.500,53$ & $94.666,08$ \\
\hline$(-)$ CMV & $(92.732,00)$ & $(67.698,65)$ & $(72.279,30)$ & $(93.620,55)$ & $(96.765,14)$ & $(92.249,88)$ & $(76.841,87)$ \\
\hline$(=)$ LB & $22.407,66$ & $16.325,87$ & $17.486,48$ & $21.293,85$ & $21.755,57$ & $21.250,65$ & $17.824,22$ \\
\hline$(-)$ DO - RYT & $(2.570,75)$ & $(1.876,03)$ & $(2.004,22)$ & $(2.565,72)$ & $(2.646,24)$ & $(2.534,15)$ & $(2.113,63)$ \\
\hline$(-)$ DO - EE & $(1.500,00)$ & $(1.500,00)$ & $(1.500,00)$ & $(1.500,00)$ & $(1.500,00)$ & $(1.500,00)$ & $(1.500,00)$ \\
\hline$(-)$ DO - DAl & $(3.000,00)$ & $(3.000,00)$ & $(3.000,00)$ & $(3.000,00)$ & $(3.000,00)$ & $(3.000,00)$ & $(3.000,00)$ \\
\hline$(-)$ DO - DP & $(4.400,00)$ & $(4.400,00)$ & $(4.400,00)$ & $(4.400,00)$ & $(4.400,00)$ & $(4.400,00)$ & $(4.400,00)$ \\
\hline$(-)$ DO - SI & $(500,00)$ & $(500,00)$ & $(500,00)$ & $(500,00)$ & $(500,00)$ & $(500,00)$ & $(500,00)$ \\
\hline$(=)$ LL & $10.436,91$ & $5.049,83$ & $6.082,26$ & $9.328,13$ & $9.709,33$ & $9.316,50$ & $6.310,59$ \\
\hline \multicolumn{1}{|c|}{ Período } & ABR-19 & MAI-19 & JUN-19 & JUL-19 & AGO-19 & SET-19 & \\
\hline$(=)$ RL & $101.725,26$ & $89.067,56$ & $102.369,39$ & $102.369,39$ & $102.369,39$ & $102.369,39$ & \\
\hline$(-)$ CMV & $(82.702,01)$ & $(74.990,30)$ & $(83.319,96)$ & $(83.319,96)$ & $(83.319,96)$ & $(83.319,96)$ & \\
\hline$(=)$ LB & $19.023,26$ & $14.077,26$ & $19.049,42$ & $19.049,42$ & $21.755,57$ & $21.250,65$ & \\
\hline$(-)$ DO - RYT & $(2.271,24)$ & $(1.988,63)$ & $(2.285,62)$ & $(2.285,62)$ & $(\mathrm{R} \$ 2.646,24)$ & $(\mathrm{R} \$ 2.534,15)$ & \\
\hline$(-)$ DO - EE & $(1.500,00)$ & $(1.500,00)$ & $(1.500,00)$ & $(1.500,00)$ & $(1.500,00)$ & $(1.500,00)$ & \\
\hline$(-)$ DO - DAl & $(3.000,00)$ & $(3.000,00)$ & $(3.000,00)$ & $(3.000,00)$ & $(3.000,00)$ & $(3.000,00)$ & \\
\hline$(-)$ DO - DP & $(4.400,00)$ & $(4.400,00)$ & $(4.400,00)$ & $(4.400,00)$ & $(4.400,00)$ & $(4.400,00)$ & \\
\hline$(-)$ DO - SI & $(500,00)$ & $(500,00)$ & $(499,00)$ & $(498,00)$ & $(497,00)$ & $(496,00)$ & \\
\hline$(=)$ LL & $7.352,01$ & $2.688,63$ & $7.364,80$ & $7.365,80$ & $7.366,80$ & $7.367,80$ & \\
\hline
\end{tabular}

Fonte: Elaborada pelos autores.

A Tabela 3 apresenta o Plano de Resultados do segundo cenário do negócio. Para a elaboração dessa tabela foram utilizados dados do Pit Stop Skol Comboio e, assim, calculouse a venda mínima necessária para um retorno do capital investido em até 12 meses.

Essa simulação tem a finalidade de verificar a viabilidade do negócio com as novas despesas que diferem do Pit Stop Skol Comboio. Porém, foi necessário vendas mínimas de $50 \%$ a mais em relação ao posto comboio para que se tenha o retorno financeiro do capital investido em até 12 meses.

A venda de $50 \%$ a mais em relação ao Pit Stop Skol Comboio proporciona vendas mensais médias de R\$102.369,39, com uma margem a contribuição de 18,6\% do Pit Stop Skol Comboio, gerando um lucro bruto médio de R\$ 19.049,39. O lucro líquido médio com o acréscimo das despesas foi de $\mathrm{R} \$ 7.363,80$, produzindo uma margem de contribuição líquida de $7,1 \%$.

Usando a mesma taxa mínima de atratividade mensal de $1 \%$, foi calculado o valor presente líquido (VPL) do Pit Stop Skol Luxemburgo e obteve-se um valor de R\$ 5.898,92. A taxa interna de retorno calculada foi de $2,57 \%$ e o payback descontado foi de 12 meses, conforme visto na Tabela 4. 
Tabela 4 - Cálculo do Payback Descontado do Segundo Cenário

\begin{tabular}{|c|c|c|c|c|c|c|}
\hline & AGO-18 & SET-18 & OUT-18 & NOV-18 & DEZ-18 & JAN-19 \\
\hline Lucro líquido & 0 & $10.436,91$ & $5.049,83$ & $6.082,26$ & $9.328,13$ & $9.709,33$ \\
\hline $\begin{array}{l}\text { Custo da } \\
\text { franquia }\end{array}$ & $(10.000,00)$ & $(10.000,00)$ & $(10.000,00)$ & $(10.000,00)$ & $(10.000,00)$ & \\
\hline Reforma civil & $(5.000,00)$ & & & & & \\
\hline Capital de giro & $(23.183,00)$ & & & & & \\
\hline Fluxo de caixa & $(38.183,00)$ & 436,91 & $(4.950,17)$ & $(3.917,74)$ & $(671,87)$ & $9.709,33$ \\
\hline $\begin{array}{c}\text { Payback } \\
\text { descontado }\end{array}$ & $(38.183,00)$ & $(37.750,42)$ & $(42.603,05)$ & $(46.405,57)$ & $(47.051,22)$ & $(37.813,13)$ \\
\hline & FEV-19 & MAR-19 & ABR-19 & MAI-19 & JUN-19 & JUL-19 \\
\hline Lucro líquido & $9.316,50$ & $6.310,59$ & $7.352,01$ & $2.688,63$ & $7.363,80$ & $7.363,80$ \\
\hline Fluxo de caixa & $9.316,50$ & $6.310,59$ & $7.352,01$ & $2.688,63$ & $7.363,80$ & $7.363,80$ \\
\hline $\begin{array}{c}\text { Payback } \\
\text { descontado }\end{array}$ & $(29.036,56)$ & $(23.150,56)$ & $(16.361,1)$ & $(13.902,78)$ & $(7.236,43)$ & $(636,08)$ \\
\hline
\end{tabular}

Fonte: Elaborada pelos autores.

Na primeira simulação alguns números chamam atenção, principalmente a variável faturamento mensal que é 50\% superior a venda do Posto Comboio. Para esse faturamento é necessário que vendas médias sejam de 62.804 de unidades de bebidas que compõe o Mix de produtos. Portanto, é necessário um investimento inicial de $\mathrm{R} \$ 38.183,65$, ou seja, um capital de 2,47 vezes superior ao capital de giro do Posto Comboio, que é de $\mathrm{R} \$ 15.455,33$.

Em conclusão, a primeira simulação mostrou-se arriscada, uma vez que depende de um valor de vendas superior a $50 \%$ da empresa usada como referência para elaboração do projeto. Mesmo com vendas superiores, obteve-se uma taxa interna de retorno (TIR) inferior ao cenário baseado no Pit Stop Comboio. Já que neste cenário, há uma separação entre o posto de gasolina e a franquia, é necessário aplicar também a alíquota do imposto de renda baseado na receita bruta. Neste caso, é necessário aumentar ainda mais o faturamento mensal para conseguir um período de payback menor de 1 ano.

\subsubsection{Terceiro Cenário}

O terceiro cenário do negócio leva em consideração uma parceria ou, melhor, um sócio. Neste cenário, o parceiro entra com a mão-de-obra (já presente na revenda de combustíveis), infraestrutura, clientes, e colabora no aluguel (desconto no valor do aluguel do terreno). As despesas operacionais com royalties de 6,5\% sobre o faturamento do litrinho e com a energia elétrica somam um valor médio de $\mathrm{R} \$ 1.500,00$. As despesas com salários são de responsabilidade do sócio que terá uma participação nos lucros de $30 \%$. A Tabela 5 apresenta o Plano de Resultados do terceiro cenário do negócio do Pit Stop Skol Luxemburgo, que destaca o Lucro Contábil (LC) e a Participação nos Lucros ou Resultados (PLR) pelo sócio.

Para análise do terceiro cenário, utilizou-se os dados de venda e margem de contribuição do Pit Stop Skol Comboio. Dessa maneira, a margem de contribuição média foi de $18,6 \%$, com um faturamento mensal médio de $\mathrm{R} \$ 68.246,26$. O sócio tem uma retirada 
mensal de $30 \%$ de um lucro operacional médio de $\mathrm{R} \$ 9.675,87$, portanto terá uma participação R\$2.902,38 no lucro da empresa.

Tabela 5 - Plano de Resultados do Terceiro Cenário

\begin{tabular}{|l|c|c|c|c|c|c|}
\hline \multicolumn{1}{|c|}{ MÊS } & SET-18 & OUT-18 & NOV-18 & DEZ-18 & JAN-19 & FEV-19 \\
\hline$(=)$ RL & $76.759,77$ & $56.016,34$ & $59.843,85$ & $76.609,60$ & $79.013,80$ & $75.667,02$ \\
\hline$(-)$ CMV & $(61.821,33)$ & $(45.132,43)$ & $(48.186,20)$ & $(62.413,70)$ & $(64.510,09)$ & $(61.499,92)$ \\
\hline$(=)$ LB & $14.938,44$ & $10.883,91$ & $11.657,65$ & $14.195,90$ & $14.503,71$ & $14.167,10$ \\
\hline$(-)$ DO - RYT & $(1.713,83)$ & $(1.250,69)$ & $(1.336,15)$ & $(1.710,48)$ & $(1.764,16)$ & $(1.689,43)$ \\
\hline$(-)$ DO - EE & $(1.500,00)$ & $(1.500,00)$ & $(1.500,00)$ & $(1.500,00)$ & $(1.500,00)$ & $(1.500,00)$ \\
\hline$(=)$ LC & $11.724,61$ & $8.133,22$ & $8.821,50$ & $10.985,42$ & $11.239,55$ & $10.977,67$ \\
\hline$(-)$ PLR & $(3.517,38)$ & $(2.439,97)$ & $(2.646,45)$ & $(3.295,63)$ & $(3.371,87)$ & $(3.293,30)$ \\
\hline$(=)$ LL & $8.207,23$ & $5.693,26$ & $6.175,05$ & $7.689,80$ & $7.867,69$ & $7.684,37$ \\
\hline \multicolumn{1}{|c|}{ MÊS } & MAR-19 & ABR-19 & MAI-19 & JUN-19 & JUL-19 & AGO-19 \\
\hline$(=)$ RL & $63.110,72$ & $67.816,84$ & $59.378,37$ & $68.246,26$ & $68.246,26$ & $68.246,26$ \\
\hline$(-)$ CMV & $(51.227,91)$ & $(55.134,67)$ & $(49.993,53)$ & $(55.546,64)$ & $(55.546,64)$ & $(55.546,64)$ \\
\hline$(=)$ LB & $11.882,81$ & $12.682,17$ & $9.384,84$ & $12.699,61$ & $12.699,61$ & $12.699,61$ \\
\hline$(-)$ DO - RYT & $(1.409,09)$ & $(1.514,16)$ & $(1.325,75)$ & $(1.523,75)$ & $1.523,75)$ & $(1.523,75)$ \\
\hline$(-)$ DO - EE & $(1.500,00)$ & $(1.500,00)$ & $(1.500,00)$ & $(1.500,00)$ & $(1.500,00)$ & $(1.500,00)$ \\
\hline$(=)$ LC & $8.973,72$ & $9.668,01$ & $6.559,09$ & $9.675,87$ & $9.675,87$ & $9.675,87$ \\
\hline$(-)$ PLR & $(2.692,12)$ & $(2.900,40)$ & $(1.967,73)$ & $(2.902,76)$ & $(2.902,76)$ & $(2.902,76)$ \\
\hline$(=)$ LL & $6.281,61$ & $6.767,61$ & $4.591,36$ & $6.773,11$ & $6.773,11$ & $6.773,11$ \\
\hline
\end{tabular}

Fonte: Elaborada pelos autores.

A retirada percentual do sócio para cobrir os custos com mão de obra e remuneração das instalações torna o negócio menos arriscado, uma vez que diluí os custos fixos do empreendedor em custos variáveis. Neste modelo de negócio o Pit Stop Skol Luxemburgo teve um resultado positivo com lucro líquido médio de $\mathrm{R} \$ 6.773,11$.

A Tabela 6 mostra a viabilidade do negócio a partir dos investimentos iniciais da concessão da franquia, ou seja, cinco prestações mensais de $\mathrm{R} \$ 10.000,00$. No investimento inicial estão inclusos os investimentos com obras civis para assentamento do container e investimentos com infraestrutura (notebook) no valor de $\mathrm{R} \$ 5.000,00$. O capital de giro mínimo necessário para a inicialização do negócio no $\mathrm{R} \$ 15.455,33$ é referente a uma semana de estoque.

Finalizando a análise financeira, com o fluxo de caixa elaborado, obteve-se o valor presente líquido (VPL) de R \$ 6.860,19 descontado a uma taxa de atratividade de $1 \%$ ano mês. O valor da Taxa Interna De Retorno (TIR) foi de 3,02\% e com um payback descontado de 11 meses. 
Tabela 6 - Cálculo do Payback Descontado da Terceira Proposta

\begin{tabular}{|c|c|c|c|c|c|c|}
\hline & AGO-18 & SET-18 & OUT-18 & NOV-18 & DEZ-18 & JAN-19 \\
\hline Lucro Líquido & 0 & $8.207,23$ & $5.692,26$ & $6.175,05$ & $7.689,80$ & $7.867,69$ \\
\hline $\begin{array}{l}\text { Custo da } \\
\text { franquia }\end{array}$ & $(10.000,00)$ & $(10.000,00)$ & $(10.000,00)$ & $(10.000,00)$ & $(10.000,00)$ & \\
\hline Reforma civil & $(5.000,00)$ & & & & & \\
\hline Capital de giro & $(15.455,33)$ & & & & & \\
\hline Fluxo de caixa & $(30.455,33)$ & $(1.792,77)$ & $(4.306,74)$ & $(3.824,95)$ & $(2.310,20)$ & $7.867,69$ \\
\hline $\begin{array}{c}\text { Payback } \\
\text { descontado }\end{array}$ & $(30.455,33)$ & $(32.230,36)$ & $(36.452,24)$ & $(40.164,70)$ & $(42.384,76)$ & $(34.898,92)$ \\
\hline & FEV-19 & MAR-19 & ABR-19 & MAI-19 & JUN-19 & JUL-19 \\
\hline Lucro Líquido & $7.684,37$ & $6.281,61$ & $6.767,61$ & $4.591,36$ & $6.773,11$ & $6.773,11$ \\
\hline Fluxo de caixa & $7.684,34$ & $6.281,61$ & $6.767,61$ & $4.591,36$ & $6.773,11$ & $6.773,11$ \\
\hline $\begin{array}{c}\text { Payback } \\
\text { descontado }\end{array}$ & $(27.659,90)$ & $(21.800,93)$ & $(15.551,16)$ & $(11.353,10)$ & $(5.221,49)$ & 849,40 \\
\hline
\end{tabular}

Fonte: Elaborada pelos autores.

\subsection{Comparação de Cenários}

Com o intuito de verificar qual o melhor cenário em que o Pit Stop Skol Luxemburgo pode ser implantado, os principais indicadores financeiros de cada um dos cenários são apresentados na Tabela 7. O primeiro cenário (A) representa o modelo de negócio em que o Pit Stop Skol Posto Comboio está implementado, com a implementação do Pit Stop Skol Luxemburgo nos moldes do Posto Comboio. O modelo de negócio do segundo cenário (B) representa a proposta de negócio independente do posto de gasolina e, finalmente, o terceiro cenário $(\mathrm{C})$ representa a proposta de negócio que conta com um sócio.

Ao comparar A com os outros cenários, verifica-se que o cenário B apresenta um faturamento de $\mathrm{R} \$ 102.369,39$ e verifica-se que o cenário $\mathrm{C}$ tem o mesmo faturamento do cenário A. Em relação ao segundo cenário, foi necessário um faturamento maior em $50 \% \mathrm{em}$ relação ao faturamento do cenário A para se ter um retorno do investimento em até 12 meses. Já no terceiro cenário, não foi necessário o aumento de faturamento para viabilizar o negócio com retorno financeiro em menos de 12 meses.

A margem de contribuição do Pit Stop Skol Posto Comboio (cenário A) foi utilizada como referência para elaboração o cálculo de lucro bruto dos outros dois cenários. Dessa maneira, a margem e contribuição dos outros cenários foram fixados em 18,61\% para a determinação do lucro bruto.

O lucro líquido dos cenários $\mathrm{A}$ e $\mathrm{B}$ se mantiveram constantes em relação ao lucro operacional, uma vez que ele foi deduzido pela retirada do sócio (no valor de $30 \%$ do lucro operacional), como no caso do cenário $\mathrm{C}$.

Ao comparar os valores de vendas dos cenários $\mathrm{C}$ e $\mathrm{B}$ com relação às vendas do Posto Comboio em Araxá, pode-se afirmar que a previsão de vendas para o bairro Luxemburgo, em Belo Horizonte, é maior. A previsão otimista é caracterizada por dois fatores demográficos da população da região centro-sul de Belo Horizonte: (i) maior densidade demográfica; e (ii) maior poder de compra. 
Tabela 7 - Análise Comparativa dos Três Cenários

\begin{tabular}{|l|c|c|c|}
\hline \multicolumn{1}{|c|}{ Cenários } & $\mathrm{A}$ & $\mathrm{B}$ & $\mathrm{C}$ \\
\hline Faturamento & $68.246,26$ & $102.369,39$ & $68.246,26$ \\
\hline Lucro Bruto & $12.699,61$ & $19.049,42$ & $12.699,61$ \\
\hline Lucro Operacional & $9.675,87$ & $7.364,57$ & $9.675,87$ \\
\hline Lucro Líquido & $9.675,87$ & $7.364,57$ & $6.728,01$ \\
\hline Margem Contribuição & $18,61 \%$ & $18,61 \%$ & $18,61 \%$ \\
\hline Margem Operacional & $14,18 \%$ & $7,19 \%$ & $14,18 \%$ \\
\hline Margem Líquida & $14,18 \%$ & $7,19 \%$ & $9,86 \%$ \\
\hline TIR & $12,02 \%$ & $2,57 \%$ & $2,84 \%$ \\
\hline VPL & $39.575,27$ & $5.898,92$ & $6.279,76$ \\
\hline Payback Descontado & 8 meses & 12 meses & 11 meses \\
\hline
\end{tabular}

Fonte: Elaborada pelos autores.

O terceiro cenário mostrou-se mais viável do que o segundo, uma vez que o faturamento de $\mathrm{C}$ é mais conservador. Com relação ao modelo de negócio do Pit Stop Skol Posto Comboio, foi calculado uma TIR e um VPL de pelo menos quatro vezes maior do que os outros cenários. Dessa maneira, o cenário A apresenta a melhor viabilidade financeira pelo fato de utilizar os funcionários da revenda de combustível e por não pagar aluguel.

\section{Conclusão}

Este trabalho busca analisar a viabilidade da abertura de um novo negócio de franquia shop in shop chamada "Pit Stop Skol na cidade de Belo Horizonte, trazendo dados e informações empíricas de uma franquia existente na cidade de Araxá, em Minas Gerais. Foram realizadas entrevistas e coleta de dados com o proprietário do negócio Pit Stop Skol do Posto. Assim, foram traçados três cenários para o negócio, com três diferentes estimativas de vendas. No primeiro cenário, o fluxo de caixa e o modo de operação do novo negócio é idêntico à realidade do Posto Comboio. Já o segundo cenário conta com despesas (aluguel e mão-de-obra extra) que não são consideradas no primeiro. Enfim, o terceiro cenário apresenta duas modificações nas despesas: a inclusão de aluguel e a remuneração do sócio.

Em relação ao modelo de negócio implantado no Pit Stop Skol do Posto Comboio, ele se mostrou mais lucrativo e rentável em relação aos outros dois cenários. Porém, para a implementação desse modelo é necessário que o proprietário do varejo de combustível seja o mesmo proprietário da franquia Pit Stop Skol.

No segundo cenário, sugere-se a utilização da mão-de-obra do próprio Pit Stop Skol e não a utilização dos funcionários do varejo de combustíveis como no caso do Pit Stop Skol Comboio. Para este cenário apresentar um retorno financeiro em até um ano, é preciso que as vendas sejam maiores em pelo menos 50\% em relação às vendas do Pit Stop Skol Comboio. Portanto, esse cenário se mostra arriscado, pois o valor mínimo de vendas necessária para ter o retorno esperado é alto quando comparado com o modelo de negócio utilizado como referencial para desenvolver o presente trabalho. 
O terceiro cenário sugere uma sociedade com o revendedor de combustíveis e, assim, remunera-se a participação do sócio com $30 \%$ do lucro líquido do empreendimento. Utilizando-se a mão-de-obra ociosa da revenda de combustíveis, consegue-se uma redução de custos e, assim, viabiliza-se o negócio. $\mathrm{O}$ cenário mostra-se atrativo para o sócio (revendedor de combustíveis), uma vez que o sócio retira mensalmente uma parcela de $30 \%$ do resultado líquido, relativo à sua participação na sociedade. Nesse sentido, o sócio tem um retorno financeiro sobre a mão-de-obra ociosa e sobre a área física não aproveitada. Portanto, o sócio não corre riscos e não realiza qualquer investimento adicional ao já realizado para a manutenção do posto de combustíveis.

Considerando todos os conceitos e reflexões desenvolvidas ao longo deste trabalho, o terceiro cenário do Pit Stop Skol Luxemburgo mostra-se viável com (i) um retorno financeiro em menos de um ano, (ii) uma proposta de vendas conservadora, e (iii) por não ser proprietário de nenhuma revenda de combustível no local estudado. Portanto, o presente plano de negócios poderá ser destinado à implementação, hipótese em que o terceiro cenário de negócio do Pit Stop Skol será levado para negociação com o proprietário da revenda de combustível e, caso haja interesse das duas partes, será estabelecido o negócio.

Este artigo pode servir de referência para trabalhos futuros de um modelo de construção de plano negócios utilizando dados públicos e dados práticos de um negócio já em operação. Cabe ressaltar que este trabalho está limitado à utilização de dados existentes, ou seja, trabalhos futuros que não têm esses dados devem realizar pesquisas de campo e de mercado para tentar aproximar e plano de negócios da realidade do mercado.

\section{$8 \quad$ Referências}

AZOULAY, P.; SHANE, S. Entrepreneurs, Contracts, and the Failure of Young Firms. Management Science, v. 47, n. 3, p. 337-358, 2001.

BOYLE, E. The Failure of Business Format Franchising in British Forecourt Retailing: A Case Study of the Rebranding of Shell Retail's Forecourts. International Journal of Retail \& Distribution Management, v. 30, n. 5, p. 251-263, 2002.

BRICKLEY, J. A.; DARK, F. H. The Choice of Organizational Form: The Case of Franchising. Journal of Financial Economics, v. 18, n. 2, p. 401-420, 1987.

BRICKLEY, J. A.; DARK, F. H; WEISBACH, M. S. An Agency Perspective on Franchising. Financial Management, v. 20, n. 1, p. 27-35, 1991.

COMBS, J. G.; KETCHEN, D. J. Can Capital Scarcity Help Agency Theory Explain Franchising? Revisiting the Capital Scarcity Hypothesis. The Academy of Management Journal, v. 42, n. 2, p. 196-207, 1999.

FRAZER, L. Causes of Disruption to Franchise Operations. Journal of Business Research, v. 54, p. 227-234, 2001. 
FULOP, C.; FORWARD, J. Insights into Franchising: A Review of Empirical and Theoretical Perspectives. The Service Industries Journal, v. 17, n. 4, p. 603-625, 1997.

HOLMBERG, S. R.; MORGAN, K. B. Franchise Turnover and Failure: New Research and Perspectives. Journal of Business Venturing, v. 18, p. 403-418, 2003.

KAUFMANN, P. J. Franchising and the Choice of Self-Employment. Journal of Business Venturing, v. 14, n. 4, p. 345-362.

LUTZ, N. A. Ownership Rights and Incentives in Franchising. Journal of Corporate Finance, v. 2, n. 1-2, p. 103-131.

MACHADO, H. V.; ESPINHA, P. G. Empreendedorismo e Franchising: Uma Combinação que Garante a Sobrevivência? Revista de Administração Mackenzie, v. 11, n. 4, p. 131-153, 2010.

MARCONI, M. A.; LAKATOS, E. M. Fundamentos de Metodologia Científica. 5a ed. São Paulo: Atlas, 2003.

MICHAEL, S. C.; COMBS, J. G. Entrepreneurial Failure: The Case of Franchisees. Journal of Small Business Management, v. 46, n. 1, p. 73-90, 2008.

NORTON, S. W. An Empirical Look at Franchising as an Organizational Form. The Journal of Business, v. 61, n. 2, p. 197-218, 1988.

OXENFELDT, A. R.; KELLY, A. O. Will successful franchise systems ultimately become wholly-owned chains? Journal of Retailing, v. 44, n. 4, p. 69-83, 1968.

RUBIN, P. H. The Theory of the Firm and the Structure of the Franchise Contract. The Journal of Law \& Economics, v. 21, n. 1, p. 223-233, 1978.

SCHREIBER, D.; SZYSZKO, F. S. Estudo da Alternativa de Franchising come Base no Caso da Franquia Doutor Resolve. Revista da Micro e Pequena Empresa, v. 8, n. 1, p. 18-31, 2014.

SEBRAE - Serviço Brasileiro de Apoio às Micro e Pequenas Empresas. Causa Mortis: o sucesso e o fracasso das empresas nos primeiros cinco anos de vida. São Paulo: Sebrae, 2014. Disponível em: <http://www.sebrae.com.br/Sebrae/Portal\%20Sebrae/UFs/SP/Anexos/ causa_mortis_2014.pdf>

SEBRAE - Serviço Brasileiro de Apoio às Micro e Pequenas Empresas. Sobrevivência das empresas no Brasil. Brasília: Sebrae, 2016. Disponível em: $<$ http://www.sebrae.com.br/Sebrae/Portal\%20Sebrae/Anexos/sobrevivencia-das-empresas-nobrasil-relatorio-2016.pdf> 